\title{
INCLUSÃO SOCIAL A PARTIR DO DIREITO À MORADIA: PROGRAMA RECIFE SEM PALAFITAS
}

\section{A Autora}

\section{Fernanda Martinez de Oliveira}

Mestranda em Administração Pública pela Escola de Administração de Empresas de São Paulo da Fundação Getúlio Vargas e pesquisadora do Programa Gestão Pública e Cidadania. 


\section{Introdução}

Valdir nos convidou com muito entusiasmo para conhecer sua nova casa: a sala, o banheiro e os quartos, todos os cômodos quase sem móveis. A grande novidade para ele eram os documentos, mostrados um a um, com muito orgulho. Agora Valdir tinha não só uma casa, mas um nome, e repetia com ênfase, em meio à embriaguez: não queria mais ser chamado de "Pato", seu antigo apelido, seu nome era Valdir. A Ponte do Limoeiro foi durante muito tempo usada como moradia por cerca de 20 pessoas na cidade do Recife (PE), dentre as quais o Valdir. A situação era bastante grave: sob a ponte está o rio e, na estrutura desta, num espaço que chegava a um pouco mais de $1,5 \mathrm{~m}$ de altura, esse conjunto de pessoas vivia absolutamente anônimo em relação à cidade.

Visando promover a inclusão social a partir da garantia do direito à moradia, a Prefeitura do Recife, no início de 2003, criou o Programa Recife Sem Palafitas, que consiste no esforço de articular diversos projetos de habitação e urbanização para as áreas mais precárias do Recife. Coordenadas pela Empresa de Urbanização do Recife (URB), as ações que compõe o Programa são bastante focalizadas: as intervenções integradas que se iniciam por projetos de habitação social buscam atender cerca de 72 mil pessoas ( $5 \%$ da população recifense ${ }^{1}$ ), que vivem não apenas em habitações de madeira construídas sob as margens dos cursos d'água, as palafitas, que emprestam o nome ao Programa, mas todas as moradias precárias, com menos de $18 \mathrm{~m}^{2}$, localizadas na orla pluvial, fluvial e área de mangue da cidade.

Principal centro da região metropolitana, no Recife as desigualdades sociais ficam claramente materializadas no modo de morar de sua população: ainda que as comunidades de alta, média e baixa renda estejam próximas territorialmente, as diferenças sociais colocam enormes distâncias entre elas ${ }^{2}$. A densidade demográfica média da cidade é de 64,8 habitantes por hectare; quando o olhar se volta para os assentamentos informais, esse indicador chega a um índice superior a 195 habitantes por hectare. Vale destacar que, segundo dados de 2000, mais de $46 \%$ da população recifense vivem nesses assentamentos que se ergueram sobre áreas de

\footnotetext{
${ }^{1} 0$ município de Recife tem 1,4 milhões de habitantes e sua região metropolitana totaliza 3,3 milhões de habitantes (IBGE 2000). ${ }^{2}$ Segundo o geógrafo Jan Bitoun, "nenhum morador de renda alta ou média mora a mais de 1.050m de uma comunidade de baixa renda". PREFEITURA DA CIDADE DO RECIFE. Cidade Saudável. Plano Plurianual 2002- 2005. V.1. Recife, 2001 apud PREFEITURA DA CIDADE DO RECIFE. Recife: Cidade Desigual. Documento elaborado para o Concurso Prêmio IPEA 40 anos, 2004 (meio magnético).
} 
alagados, rios e morros, ocupando cerca de 15\% do espaço da cidade, enquanto isso, as populações de maior poder aquisitivo, apropriaram-se das terras planas e secas.

Os efeitos da expansão da cidade para além das margens de seus rios, morros e alagados não é um fenômeno novo no Recife. As primeiras habitações erguidas em aterros nas margens dos rios, os mocambos, são de 1920. Desde essa época, seguiu-se uma série de intervenções ${ }^{3}$ que, guiadas por diferentes interesses, abordaram a questão e fomentaram a criação de um ambiente político e institucional propício para a promoção de direitos sociais a partir do direito de moradia. O reconhecimento da existência de interesse social na ocupação de áreas públicas e privadas por assentamentos populares, irregulares quanto à infra-estrutura urbana e direito a posse da terra, iniciou-se a partir da instituição das Zonas Especiais de Interesse Social (ZEIS), em 1983. Quatro anos mais tarde, quando da sua regulamentação, criou-se o Plano de Regularização das Zonas de Interesse Social - PREZEIS, fruto da mobilização dos movimentos sociais organizados e do acúmulo de experiências anteriores do poder público municipal. O Plano, cujo principal objetivo é a promoção de melhorias no padrão habitacional, a urbanização e a regularização fundiária de áreas pobres, por meio da gestão participativa dos recursos e prioridades, não atingiu resultados expressivos durante seus 15 anos de existência e sete mudanças na gestão municipal: apenas três áreas concluíram a urbanização, 304 famílias foram reassentadas, 497 títulos de concessão de direito real de uso foram concedidos e 33 intervenções pontuais de urbanização realizadas (Miranda, 2003).

É a partir das intervenções realizadas no âmbito do Programa de Saúde Ambiental ${ }^{4}$, estudos realizados nas áreas pobres da cidade e, principalmente, depois da visita à comunidade de Brasília Teimosa, realizada no início de 2003, pelo presidente Luis Inácio Lula da Silva, na época recém empossado, que os gestores públicos reconstroem a concepção do Programa, ou seja, o reconhecimento pelo poder municipal da necessidade de promover intervenções integradas nas áreas de risco nos alagados.

\footnotetext{
${ }^{3}$ Como a pioneira Liga Social Contra o Mocambo, do final dos anos 1930, cujo enfoque privilegiava a segregação social e, mais recentemente, o Programa Barracões nos Bairros (1978-1981) e o Programa PROMORAR (1979).

${ }^{4}$ Iniciativa da Prefeitura do Recife cujo objetivo "é implantar uma política de saúde universal, integrada e eqüitativa, com foco no meio ambiente, por meio da identificação, eliminação ou redução dos riscos". Sob responsabilidade da Secretaria Municipal de Saúde, as ações se articulam localmente via os Agentes de Saúde Ambiental, que visitam os bairros, eliminando focos de doenças com bons resultados. Foi escolhida finalista no Prêmio Gestão Pública e Cidadania em 2003.
} 


\section{O Programa Recife Sem Palafitas: descrição e metodologia de ação}

O Programa Recife Sem Palafitas, que tem por objetivo a erradicação das habitações de risco nas comunidades que vivem em zonas de alagados, consiste em um conjunto articulado de projetos e atividades inter e intragovernamentais. Ainda que se caracterizem por diferentes autorias, temporalidades e fontes de financiamento, esses projetos passaram, a partir do início de 2003, a ter seu foco voltado para a promoção do direito à moradia e a inserção social na cidade desse grupo específico de pessoas. Iniciativa da Prefeitura do Recife, as ações do Programa estão sob a responsabilidade da Empresa de Urbanização do Recife que, além de coordenar as ações, é responsável pela execução das obras e pela captação de recursos externos.

Concebido de forma integrada, o Programa prevê não apenas ações de reassentamento das famílias e reurbanização das áreas desocupadas, mas um conjunto amplo de intervenções no momento de pós-ocupação, abrangendo as áreas de saúde, educação, qualificação profissional e gestão condominial, além das ações de recuperação ambiental. Nesse sentido, foram eleitas três frentes de atuação - intervenções físicas, intervenções sociais e integração institucional que estão contempladas na metodologia de ação do Programa:

Gráfico 1: Diagrama metodológico do Programa Recife Sem Palafitas 


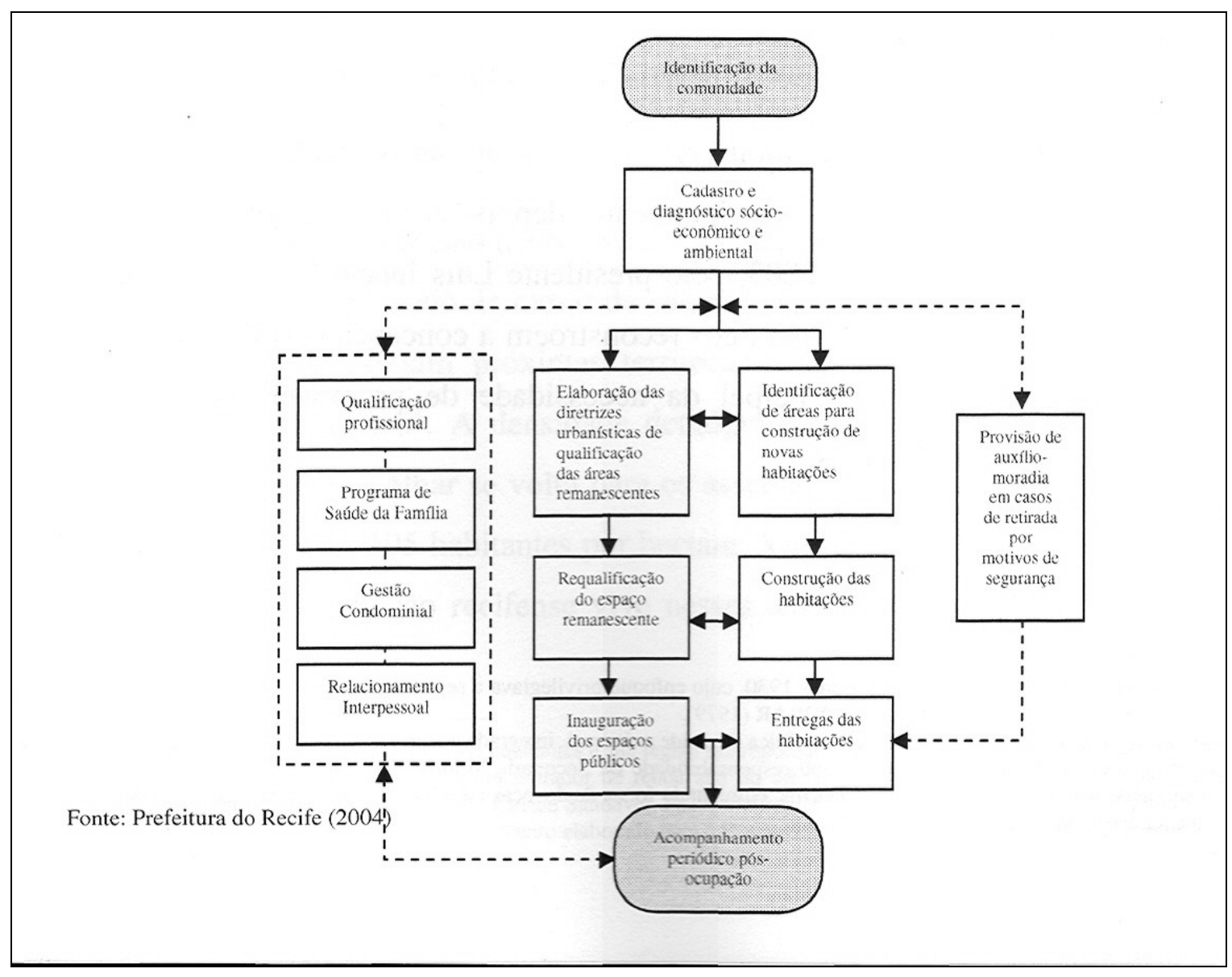


O primeiro passo dessa metodologia é a realização de pesquisas qualitativas e quantitativas por consultorias contratadas pela Prefeitura, a fim de construir um cadastro socioeconômico das populações e delimitar as áreas-alvo. Segue-se a identificação dos espaços disponíveis para a realocação das famílias e a elaboração de planos urbanísticos e arquitetônicos para as áreas desocupadas e as novas moradias. As obras de construção dos novos conjuntos habitacionais, as operações de retirada e demolição das palafitas são os passos seguintes. Em situações de risco iminente, como no caso da intervenção na comunidade de Brasília Teimosa, as famílias que desocupam suas casas passam a receber temporariamente auxílio-moradia no valor de R\$ 151,00 por mês, até o término das obras. Há também casos de indenização pela desocupação de casas para a realização das intervenções de requalificação urbana.

As novas casas e apartamentos têm dois quartos, um banheiro, sala, cozinha e uma pequena área de serviço, totalizando 39,39 $\mathrm{m}^{2}$. Com um custo médio de $\mathrm{R} \$ 14.150,00^{5}$, as novas unidades estão localizadas em áreas próximas àquelas desocupadas ${ }^{6}$. Dado que as orlas pluviais, fluviais e a área de mangues são áreas de proteção ambiental, nas quais o uso e ocupação do solo é bastante restrito, não há como as famílias permanecerem no mesmo local em que viviam. A maior parte dos conjuntos adota a tipologia vertical (prédios com cerca de quatro andares) uma vez que há dificuldades em encontrar espaços disponíveis na cidade para a construção de novas moradias.

Antes da mudança, realiza-se o sorteio das habitações - considerando as relações de vizinhança prévias e as dificuldades de locomoção (os idosos, por exemplo, tem a preferência para os andares térreos) - e a escolha dos representantes de cada bloco. Estes serão os responsáveis pela gestão dos espaços coletivos do condomínio e, por esse motivo, participam das atividades de capacitação para a gestão condominial, as primeiras ações no período de pós-ocupação.

A integração das ações das diferentes secretarias municipais no território se dá nesse momento, quando esses órgãos passam a promover ações nas comunidades reassentadas e circunvizinhas, de modo a estimular a fixação nos novos espaços urbanos e promover o acesso

\footnotetext{
12 CADERNOS GESTÃO PÚBLICA E CIDADANIA
}

${ }^{5}$ Segundo o "Estudo de Avaliação de Experiência Brasileira sobre Urbanização de Favelas e Regularização Fundiária", realizado pelo Instituto Brasileiro de Administração Municipal (IBAM 2002), na média nacional, novas unidades habitacionais de interesse social têm 36,52m² e custo médio de R\$11.836,71.

${ }^{6}$ A maior parte dos assentamentos irregulares está localizada em áreas municipais (40\%) e particulares (35\%). Todos os novos assentamentos estão sendo construídos em terrenos do município. 
a direitos. Nos conjuntos habitacionais inaugurados, paulatinamente, são implementadas ações de saúde (Programa Saúde da Família, Secretaria Municipal de Saúde), educação (BolsaEscola, Secretaria Municipal de Educação), qualificação e inserção profissionais (Secretaria de Desenvolvimento Econômico).

\section{Articulação organizacional e engenharia financeira}

O Programa Recife Sem Palafitas é uma iniciativa da Prefeitura construída a partir do reconhecimento da necessidade de focalização de projetos próprios, como também daqueles realizados em parceria com os governos federal e estadual. Apesar da disputa partidária entre os governos estadual e municipal, há sinergia na implementação das ações, principalmente via o Programa PROMETROPÓLE, que utiliza recursos do Banco Internacional de Reconstrução e Desenvolvimento (BIRD), atualmente destinados para a urbanização da bacia do Rio Beberibe, envolvendo os municípios de Recife e Olinda. Além disso, o governo estadual responde pelo abastecimento de água e operação do sistema de saneamento nos novos conjuntos, como também pelo licenciamento ambiental necessário as intervenções.

Em relação ao governo federal, o Ministério das Cidades é reconhecido pelos gestores públicos municipais como o principal parceiro da Prefeitura nas ações do Programa Recife Sem Palafitas. Praticamente todas as intervenções contam com o apoio do Ministério, seja por meio do repasse de verbas. Para a habitação, saneamento, regularização fundiária e recuperação urbanística, seja por estar em consonância com as políticas urbanas estabelecidas no nível federal. Nesse sentido, destaca-se o Habitar-Brasil, programa criado pelo governo Federal na gestão 1995-1998. O Programa, que opera fundos captados pela União junto ao Banco Interamericano de Desenvolvimento (BID), embora solicite contrapartida de recursos próprios, não exige o endividamento dos municípios, o que o toma uma das principais fontes de recursos para grande parte nas iniciativas de urbanização de favelas no País (IBAM 2002).

A Fundação Odebrecht e a Fundação Banco do Brasil também são aliadas importantes para o aparte de recursos, implementação de ações e consolidação da metodologia do Programa. Além disso, bancos públicos como o Banco Nacional de Desenvolvimento Econômico e Social (BNDES), a Caixa Econômica Federal e o Banco no Nordeste são identificados como 
organizações que fornecem apoios por meio de financiamentos, aporte de recursos para a urbanização e oferta de micro-crédito para pequenos empreendedores, respectivamente.

Pelo fato de consistir em um grande "guarda-chuva" que abriga diferentes projetos, o Programa Recife Sem Palafitas não dispõe de rubrica orçamentária própria: o total de recursos investidos até o final de 2004, na ordem de mais de R\$ 27 milhões, são a somatória dos orçamentos de cada iniciativa que o compõe. As ações concretizam uma engenharia financeira complexa, que compreendem recursos próprios da Prefeitura (30,32\%), do Governo Estadual/BIRD (45,30\%), do Orçamento Geral da União/BID (11,48\%) e de fontes privadas como a Fundação Banco do Brasil (6,67\%) e Fundação Odebrecht (5,43\%).

\section{Projetos em destaque: Brasília Teimosa e Beira Rio}

\section{Brasília Teimosa}

O mês de agosto de 2004 foi diferente na Orla marítima de Brasília Teimosa: as marés altas, que costumavam derrubar barracos e causar grandes tragédias, não foi mais motivo de medo da população e razão de plantão de jornalistas na comunidade a espera de desgraças. Cerca de 2.500 pessoas que viviam, literalmente, à sua margem, foram removidas dessa zona de risco no início do ano, situação emergencial pelo perigo iminente de vida e, por outro lado, também pela proximidade das eleições municipais.

Ocupação que tem sua origem na mesma época da criação da capital federal, Brasília Teimosa tem um histórico de confrontos com o poder público e grande politização. Sua faixa litorânea já foi alvo de diversas intervenções governamentais que consistiram na retirada das populações e de suas habitações da zona de risco. Essas ações ocorreram em diferentes momentos na década de 1980 (1982, 1986 e 1989), quando as famílias foram realocadas em conjuntos habitacionais construídos especialmente para essa finalidade, como a Vila da Prata, a Vila Moacir Gomes e a Vila Teimosinho, respectivamente. Entretanto destaca-se o fato que dessas intervenções não se seguiu a concretização das ações de urbanização planejadas para a orla (obras de contenção do mar, construção do aterro hidráulico, implantação de trecho viário, dentre outras), o que deixava a área em questão a mercê de novas invasões, que ocorriam após as retiradas. 
Novos assentamentos eram construídos sobre as águas e ao problema não se dava uma solução definitiva.

Foi somente no início de 2003 que a Prefeitura, com o aporte de recursos do Ministério das Cidades, aliou a remoção das palafitas a um conjunto integrado de ações urbanísticas, ambientais e sociais. Das cerca de 560 famílias que viviam na orla marítima e estão a espera da construção das novas moradias - Projeto Habitacional Casarão do Cordeiro, que também será destinado a população da Vila do Vintém 2, que vive nas margens do rio Capibaribe, parte recebe auxílio-moradia, parte participa de capacitação em atividades de construção civil para a construção de suas próprias casas, dentro da chamada "Operação Trabalho" (projeto de construção de moradias que, com recursos da Caixa Econômica Federal, utiliza a mão-de-obra local). As ações de urbanização da orla de Brasília Teimosa, praticamente finalizadas, consistem na reconstrução do muro de proteção entre o mar e o continente, no alargamento da faixa de praia e sua requalificação ambiental, como também pela construção de uma avenida à beira mar, já apelidada de "Brasília Formosa".

"Tinha de levar meus filhos nos ombros para que eles não chegassem molhados na escola", lembra uma moradora de palafitas, que atualmente recebe o auxílio-moradia, o qual usa para pagar o aluguel de uma casa também em Brasília Teimosa e cobrir outros gastos, e foi inserida no Programa Bolsa-Escola. O cheiro de esgoto, o medo da maré alta e todos os artifícios criados para conviver com as péssimas condições de moradia são lembranças quase distantes para as famílias que aguardam a construção de suas novas casas. Alguns dos moradores antigos de Brasília Teimosa se dizem satisfeitos por terem voltado a freqüentar a praia ("antes eu tinha nojo"). Outros, principalmente aqueles que têm suas casas em áreas que serão desapropriadas pela Prefeitura para a criação de espaços de lazer e equipamentos comunitários na avenida construída à beira-mar, reconhecem as melhorias na orla, mas estão descontentes com a retirada de suas casas para a concretização dessas ações. "Para que construir um estacionamento se não temos carros por aqui?". Esse é o questionamento de uma moradora que vive a 30 anos na comunidade e atualmente tenta um acordo com a Prefeitura em relação ao valor da indenização por sua casa que agora esta à beira da nova pista.

As lideranças comunitárias relembram o histórico de lutas na comunidade e mostram com orgulho antigos projetos para a orla, como o "Projeto Teimosinho", de 1979, que já previa uma 
série de intervenções que foram concretizadas recentemente. Pontuam também que foi difícil mobilizar a população das palafitas, que estava descrente em relação às ações governamentais, pois sempre eram procuradas antes das eleições com muitas promessas. Hoje, há uma comissão da beira-mar que, em seus encontros semanais, chega a reunir mais de 100 pessoas.

\section{Conjunto Habitacional Beira Rio da Torre}

As 320 moradias das comunidades Arlindo Gouveia e José de Holanda, que estavam localizadas na Madalena, bairro de classe média do Recife, além de outras dimensões de pobreza, caracterizavam-se pela localização em áreas de risco nos alagados do rio Capibaribe, foram as primeiras reassentadas com o direcionamento dos recursos do Projeto HabitarBrasil/BID para as populações de palafitas.

Inaugurado em março de 2004, o conjunto tem 320 moradias divididas em 10 blocos de apartamentos de quatro pavimentos (térreo e três andares) e uma lavanderia comunitária. É nesta iniciativa que as ações articuladas de pós-ocupação estão em processo mais avançado dentro do Programa Recife Sem Palafitas. Em relação à capacitação e geração de trabalho e renda, por exemplo, em parceria com a Secretaria Municipal de Desenvolvimento Econômico e com a Secretaria Municipal de Educação, estão sendo promovidos cursos profissionalizantes, alguns dos quais voltados para a formação de empreendimentos solidários. O conjunto dispõe de um centro de comercialização, no qual os moradores que já tinham um pequeno negócio em suas antigas casas, em breve poderão fazer uso de boxes para fins comerciais, junto com outros residentes contemplados para utilizar o espaço por meio de sorteio. De modo a orientar os empreendedores para a escolha do tipo de negócio a ser implementado, merece destaque a pesquisa de vocação econômica do entorno realizada pelo poder público.

As ações de gestão condominial iniciaram-se antes da mudança, com a definição dos moradores de cada bloco (observando critérios de vizinhança e também as desigualdades de renda) e a realização de encontros por bloco para a definição de novas regras de convivência. Depois se seguiu o sorteio dos apartamentos, o reassentamento das famílias e a eleição dos representantes de cada bloco. Estes são acompanhados pela Prefeitura por meio de reuniões 
semanais onde, por exemplo, se discute a arrecadação das despesas coletivas e como fazer a contabilidade destas, como também as formas de se relacionar com os moradores que estão encontrando problemas para adaptar-se à nova forma de morar. Os jovens, identificados como os mais resistentes às novas regras de convivência, também são focos de atuação por meio da realização de cursos e seminários com foco em educação ambiental.

Ainda que a dimensão jurídica esteja contemplada nas ações, a população beneficiária ainda aguarda a regularização das novas habitações. Nesse sentido, destaca-se, a partir de entrevistas com os gestores públicos, o enfoque nas relações de gênero que será dado nesse momento do processo, com o privilégio das mulheres para a titularidade das novas residências. Não é a questão da segurança da posse um problema posto no momento pós-ocupação segundo os moradores, mas dificuldades de adaptação às novas moradias que não foram minimizadas com as ações de pós-ocupação da Prefeitura. Não houve, por exemplo, um cuidado específico com a preparação para o uso do banheiro e do gerenciamento do uso da água e da energia elétrica.

Para quem nunca teve um banheiro em casa, usar o sanitário e o chuveiro é uma novidade que pode se tornar um grande problema. Alguns moradores, por exemplo, levaram um susto com os elevados valores das contas de água e luz chegadas um mês após a mudança. Depois desse incidente eles se organizaram, foram ao PROCON e conseguiram ser incluídos no pagamento das tarifas mínimas. Alguns problemas construtivos, a exemplo de rachaduras e vazamentos, também identificados pelos moradores como pontos fracos da intervenção. Observou-se também que a urbanização e a recuperação ambiental da área remanescente ainda não concluída.

\section{Dificuldades e fragilidades}

Uma dimensão das dificuldades observadas no Programa Recife Sem Palafitas aparece no momento pós-ocupação: se faz presente nas entrevistas com a população a necessidade de um maior cuidado com a preparação para a nova forma de morar, especialmente ressaltadas no Conjunto Habitacional Beira Rio. Além dos manuais (quase) técnicos sobre os apartamentos, distribuídos após a mudança, coloca-se como necessidade a construção de uma relação mais próxima com a totalidade dos moradores de modo a ajudá-los a enfrentar dificuldades de adaptação cultural como, por exemplo, o uso do banheiro. 
Outro obstáculo notado no Programa é a inexistência da preocupação com as necessidades diferenciadas das pessoas portadoras de deficiência. Mesmo que ainda não tenham ocorrido casos específicos nesse sentido, o poder público não está preparado para atender as demandas dos portadores de necessidades especiais nos conjuntos habitacionais de interesse social: a única iniciativa que aborda esse problema é a destinação dos apartamentos em andares térreos para pessoas com dificuldades de locomoção ${ }^{7}$.

O incipiente processo de participação também é uma limitação presente nesta iniciativa: ainda que no discurso oficial seja mencionado o diálogo com a comunidade por meio do Orçamento Participativo e das Comissões de Urbanização e Legalização da Posse da Terra (as COMLUS, espaços de participação do PREZEIS), o Programa foi apresentado de forma superficial nesses fóruns. Além disso, chama a atenção a baixa articulação com os conselhos municipais, movimentos sociais, organizações não-governamentais e universidades, atores que tem uma longa trajetória de atuação em relação à promoção do direito à moradia no Recife. No caso de Brasília Teimosa, contudo, destaca-se a formação, por iniciativa de moradores locais, da comissão da beira-mar, que vem acompanhando as intervenções da Prefeitura na comunidade. Nesse sentido, coloca-se como desafio a ampliação dos processos democráticos de tomada de decisão, principalmente na direção do fortalecimento e da articulação entre os fóruns participativos já existentes.

A alta "rentabilidade política" de intervenções no campo da habitação social é uma dimensão que deve ser considerada, sobretudo em um ano de eleições municipais. Nesse sentido, ainda que o Programa comporte projetos e atividades articulados à garantia de recursos externos e a uma experiente equipe de servidores públicos fixos, não há a garantia da permanência e da continuidade das ações.

A inexistência de um banco de dados organizados pelo Programa, que agregue os cadastros socioeconômicos das diferentes áreas da cidade também é um fator limitador seja das atividades gerenciais e de planejamento de ações, seja para o monitoramento e avaliação das diversas iniciativas já implementadas. A integração entre os diferentes bancos de dados da Prefeitura também iria ser positiva nesse sentido. Atualmente, ainda que as ações estejam

\footnotetext{
${ }^{7}$ Concretizando essa preocupação a Prefeitura de Porto Alegre incorporou soluções simples e eficazes em moradias de interesse social em um de seus projetos habitacionais. Ao custo adicional de aproximadamente R 2 mil por unidade habitacional, garante-se a acessibilidade aos portadores de necessidades especiais. O projeto "Unidade Habitacional Acessível a Pessoas Portadoras de Deficiência em Loteamentos de Habitação de Interesse Social" foi finalista do Premio Gestão Pública e Cidadania em 2003.
} 
integradas no território, não há um sistema informativo que concentre as informações sobre a cidade.

\section{Síntese dos principais resultados alcançados e lições aprendidas}

Pode-se afirmar que as ações do Programa Recife Sem Palafitas atingem a cidade de maneira marginal, considerando a magnitude do problema: 65 das 97 áreas identificadas pela Prefeitura como objeto potencial de intervenção não têm recursos captados ou intervenção programada. Ainda que mais de 750 famílias tenham sido diretamente beneficiadas ${ }^{8}$ pelas ações em Brasília Teimosa, na Ponte do Limoeiro ${ }^{9}$ e nas comunidades de Arlindo Gouveia e José de Holanda, há ainda mais de 17 mil famílias vivendo nas áreas de risco nas zonas de alagado. Contudo, se comparados aos resultados obtidos pelo PREZEIS, O Programa teve um resultado expressivo considerando seu pouco tempo de funcionamento.

Ainda no que concerne aos resultados obtidos, vale ressaltar que cerca de 1.200 pessoas participaram de cursos de capacitação nas áreas de construção civil, computação, reciclagem, cabeleireiro, bordado, dentre outras, como também em de atividades de educação ambiental e gestão de condomínios. Mesmo que não haja dados disponíveis sobre o perfil dos participantes e em relação à participação de mulheres, homens e jovens nessas atividades, identifica-se o potencial dessa iniciativa em termos da promoção do desenvolvimento local a partir de ações de moradia popular.

Destaca-se também a utilização de mão-de-obra local em alguns dos projetos (Casarão do Cordeiro e Santo Amaro), que além de promover a capacitação, gera alternativas de geração de emprego e renda. Nesse sentido, destaca-se a necessidade de consolidação do Decreto Municipal $n^{0} 18.222$ de 1999, que estabelece nos editais de licitação, 60\% da mão-de-obra a ser empregada pelas empreiteiras seja da comunidade a ser beneficiada.

Outro fator importante a ser considerado é o aprendizado gerado a partir da integração de diferentes secretarias a partir de uma intervenção social e territorial: a metodologia criada permite uma abordagem integrada da problemática do uso e ocupação do solo urbano. Essa metodologia pode trazer aprendizados e ser replicada em outros municípios e Estados na promoção de ações de política habitacional de interesse social.

\footnotetext{
${ }^{8}$ Dado que não considera os 28 mil habitantes de Brasília Teimosa, também beneficiados com a reurbanização da orla marítima.

${ }^{9}$ As pessoas que viviam na Ponte do Limoeiro foram reassentadas no Conjunto Habitacional Santo Amaro.
} 
Além disso, destaca-se a sinergia criada entre diferentes esferas de governo que, ao invés de sobrepor esforços e recursos, provocando o conflito de ações, têm agido de maneira conjunta para abordar a questão do direito à moradia. Essa também é uma lição que pode ser aprendida pelos governos em todos os níveis.

\section{Considerações finais}

A vida cotidiana começa pelo lar, espaço da família e da segurança, o "ambiente amigável" que John Friedmann ${ }^{10}$ identifica como uma das vertentes para a compreensão do processo de inclusão social. O ponto de partida desse processo no Recife é justamente a habitação: a partir da promoção do direito à moradia, a Prefeitura vem articulando uma série de iniciativas que vão do acesso à documentação à inclusão em atividades econômicas.

O Programa Recife Sem Palafitas, ao abordar a problemática da habitação social e do uso e ocupação do solo por meio de ações permanentes de urbanização, é pioneiro quando comparado às práticas anteriores. Isso fica muito claro no caso de Brasília Teimosa, onde as intervenções na década de 1980 foram pautadas por ações pontuais, as quais permitiam que novas invasões ocorressem. As ações realizadas pela Prefeitura do Recife, com a criação da avenida à beira-mar, transformaram o espaço e a relação entre a comunidade, o mar e o meio urbano.

A orientação das ações a partir de uma lógica voltada para a inclusão social também é um fator de inovação. Grande parte das intervenções em assentamentos populares no Recife foi orientada por interesses do mercado imobiliário. As pessoas eram expulsas e as áreas remanescentes apropriadas pelos representantes do poder econômico local. Atualmente as ações não são mais guiadas por essa lógica, mas pelo respeito ao direito à moradia das populações pobres.

A preocupação com a gestão condominial, expressa na realização de oficinas com os representantes da população beneficiária, diferencia essa iniciativa em relação às práticas governamentais de moradia convencionais. As dificuldades de adaptação a uma nova forma de relação coletiva são um grande problema nos projetos de habitação que optam pela 
e o processo de implementação das ações vem gerando muitos aprendizados para a equipe do Programa.

A metodologia aplicada, que expressa o entendimento da complexidade e da heterogeneidade da pobreza, é outra dimensão da inovação contida no Programa. Ao iniciar o processo pela identificação das áreas de risco, promovendo a realização de cadastros socioeconômicos, percebe-se a preocupação em conhecer melhor os cidadãos e a cidade de modo a ter mais elementos para planejar e implementar as intervenções de forma integrada. As ações no momento de pós-ocupação, que privilegiam não apenas a questão da moradia, mas da educação, saúde e geração de emprego e renda, possibilitam a construção de uma inclusão integral e da criação de condições para que as pessoas possam empreender uma nova inserção na sociedade e no ambiente urbano.

Os processos gerados a partir do Programa Recife Sem Palafitas estão conseguindo colocar algumas luzes, somar esforços e produzir resultados sobre a situação dramática em que vivem milhares de pessoas na cidade. Contudo, erradicar as habitações de risco e, mais do que isso, equacionar a problemática da habitação no Recife, é uma tarefa que não será resolvida por uma única gestão, mas a partir do momento que se tornar prioridade em todos os níveis de governos. 


\section{Referências bibliográficas}

Instituto Brasileiro de Administração Municipal - IBAM. Estudo de Avaliação da Experiência Brasileira sobre Urbanização de Favelas e Regularização Fundiária - RELATÓRIO FINAL Vol. I: Resultados das Análises. Rio de Janeiro: outubro, 2002 (relatório de pesquisa). Disponível em: http://www.cidades.gov.br

Instituto Brasileiro de Administração Municipal - IBAM. Estudo de Avaliação da Experiência Brasileira sobre Urbanização de Favelas e Regularização Fundiária - RELATÓRIO FINAL Vol. II: Consolidação das Análises - PARTE I e II. Rio de Janeiro: outubro, 2002 (relatório de pesquisa). Disponível em: http://www.cidades.gov.br

MIRANDA, Lívia. O Prezeis do Recife: 15 Anos da construção de uma política habitacional de interesse social no município. Revista Proposta, N 95, dez 2002/fev 2003.

Disponível em: http://www.ippur.ufrj.br/observatorio/redehabitat/rmre.htm

Instituto PÓLIS. Regularização da terra e da moradia: o que é e como implementar. Instituto PÓLIS: outubro de 2002. Disponível em: http://www.polis.org.br

PREFEITURA DA CIDADE DO RECIFE. Recife: Cidade Desigual. Documento elaborado para o Concurso Prêmio IPEA 40 anos, 2004 (meio magnético).

SPINK, Peter. A Heterogeneidade da pobreza: implicações para ação. Trabalho apresentado no III Congresso Brasileiro de Prevenção em DST / AIDS, Rio de Janeiro - RJ, dez. 1999. 